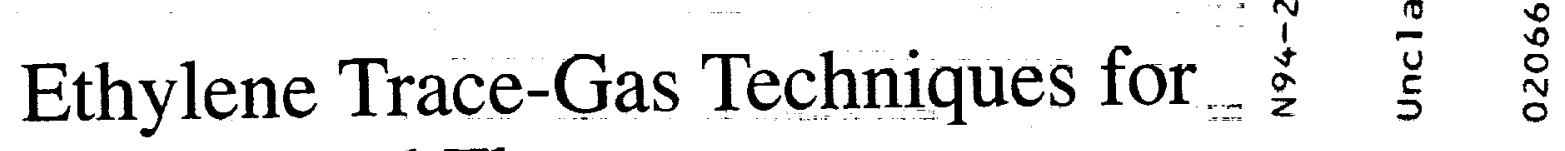
High-Speed Flows

David O. Davis and Bruce A. Reichert Lewis Research Center Cleveland, Ohio

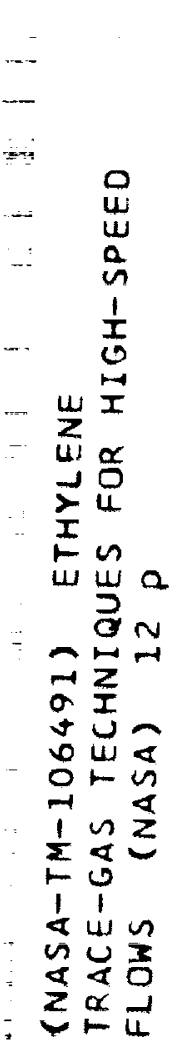

Prepared for the 32nd Aerospace Sciences Meeting and Exhibit sponsored by the American Institute of Aeronautics and Astronautics Reno, Nevada, January 10-13, 1994 


\title{
Ethylene Trace-Gas Techniques for High-Speed Flows
}

\author{
David O. Davis* and Bruce A. Reichert* \\ National Aeronautics and Space Administration \\ Lewis Research Center \\ Cleveland, Ohio 44135
}

Abstract

Three applications of the ethylene trace-gas technique to high-speed flows are described: flow-field tracking, air-to-air mixing, and bleed mass-flow measurement. The technique involves injecting a non-reacting gas (ethylene) into the flow field and measuring the concentration distribution in a downstream plane. From the distributions, information about flow development, mixing and mass-flow rates can be determined. The trace-gas apparatus and special considerations for use in high-speed flow are discussed. A description of each application, including uncertainty estimates is followed by a demonstrative example.

\section{Nomenclature}

$\begin{array}{ll}A & =\text { area } \\ D & =\text { diameter } \\ f & =\text { friction factor } \\ L & =\text { length } \\ \dot{m} & =\text { mass-flow rate } \\ m f & =\text { mass fraction } \\ M & =\text { Mach number or molecular weight } \\ N & =\text { number of moles } \\ \mathrm{ppm} & =\text { parts per million } \\ P & =\text { static pressure } \\ P_{t} & =\text { total pressure } \\ R e_{D} & =\text { Reynolds number based on diameter } \\ \mathrm{sl} / \mathrm{m} & =\text { standard litres per minute } \\ \mathrm{sml} 1 / \mathrm{m} & =\text { standard millilitres per minute } \\ W & =\text { uncertainty of a variable } \\ \bar{W} & =\text { fractional non-dimensional uncertainty } \\ v & =\text { volume (mole) fraction } \\ x, y, z & =\text { cartesian coordinate system } \\ \bar{y}, \bar{z} & =\text { coordinates of centroid } \\ \alpha & =\text { shock generator deflection angle } \\ \gamma & =\text { ratio of specific heats } \\ \delta_{0} & =\text { undisturbed boundary layer thickness } \\ \rho & =\text { density } \\ \sigma_{y}^{2}, \sigma_{z}^{2} & =\text { variances } \\ \sigma_{y} z & =\text { covariance } \\ & \end{array}$

'Research Engineer, Inlet, Duct, and Nozzle Flow Physics Branch.

Copyright 1994 by the Ameriem Institute of Aerometics and Astroneution, Ho. No copyright is eswerted in the Upired Stares moder Title 17, US. Code. The US. Governmeat bas

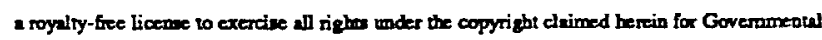
puposes. All other rights are reverved by the copyright owner.

\section{Subscripts}

$$
\begin{aligned}
& \text { air } \quad=\text { pertaining to air } \\
& \text { eth } \quad=\text { pertaining to ethylene }
\end{aligned}
$$

\section{Introduction}

In recent years, ethylene trace-gas techniques have been successfully applied to the analysis of fluid flow problems-where the host fluid medium is air-at the NASA Lewis Research Center. The ethylene trace-gas technique is a valuable tool for several reasons: it is relatively inexpensive, it is easy to use, and it is a source of Lagrangian flow-field data. Although others have used ethylene trace-gas techniques before, ${ }^{1-8}$ they have been restricted to applications where the primary velocity component was very low-in all cases the Mach number was less than 0.1. Much of the development of the ethylene trace-gas technique at NASA Lewis has concentrated on extending the applicability to higher speed flows. Some of this development work was reported by Reichert et al., ${ }^{9,10}$ where the technique was successfully applied to the analysis of high subsonic air flow through an aircraft transition duct. More recently, the technique has been extended to include the analysis of supersonic flow-fields. At present, the technique has been successfully applied in flows up to Mach 4.

In general, the trace-gas technique involves injecting and tracking a nonreacting discernible foreign gas in the host flow field being investigated. Information about the host flow field is acquired by measuring the concentration of the trace-gas at many locations downstream of the point of injection. In studies where the fluid medium is air, ethylene $\left(\mathrm{C}_{2} \mathrm{H}_{4}\right)$ is a particularly attractive trace-gas for the following reasons:

1. The molecular weight of ethylene, 28.05 , is nearly the same as air, 28.97, thus minimizing the effect of buoyancy forces on the motion of the trace-gas.

2. Under normal circumstances, ethylene and other hydrocarbon gases are only found in very minute quantities in air.

3. The mean concentration of ethylene, or any hydrocarbon gas, can be measured very accurately with a flame ionization detector.

In this paper, three applications of the ethylene tracegas technique are described: (1) flow-field tracking, (2) air-to-air mixing, and (3) bleed mass-flow measurement. Schematics of the ethylene trace-gas system for the three applications are shown in Fig. 1. 


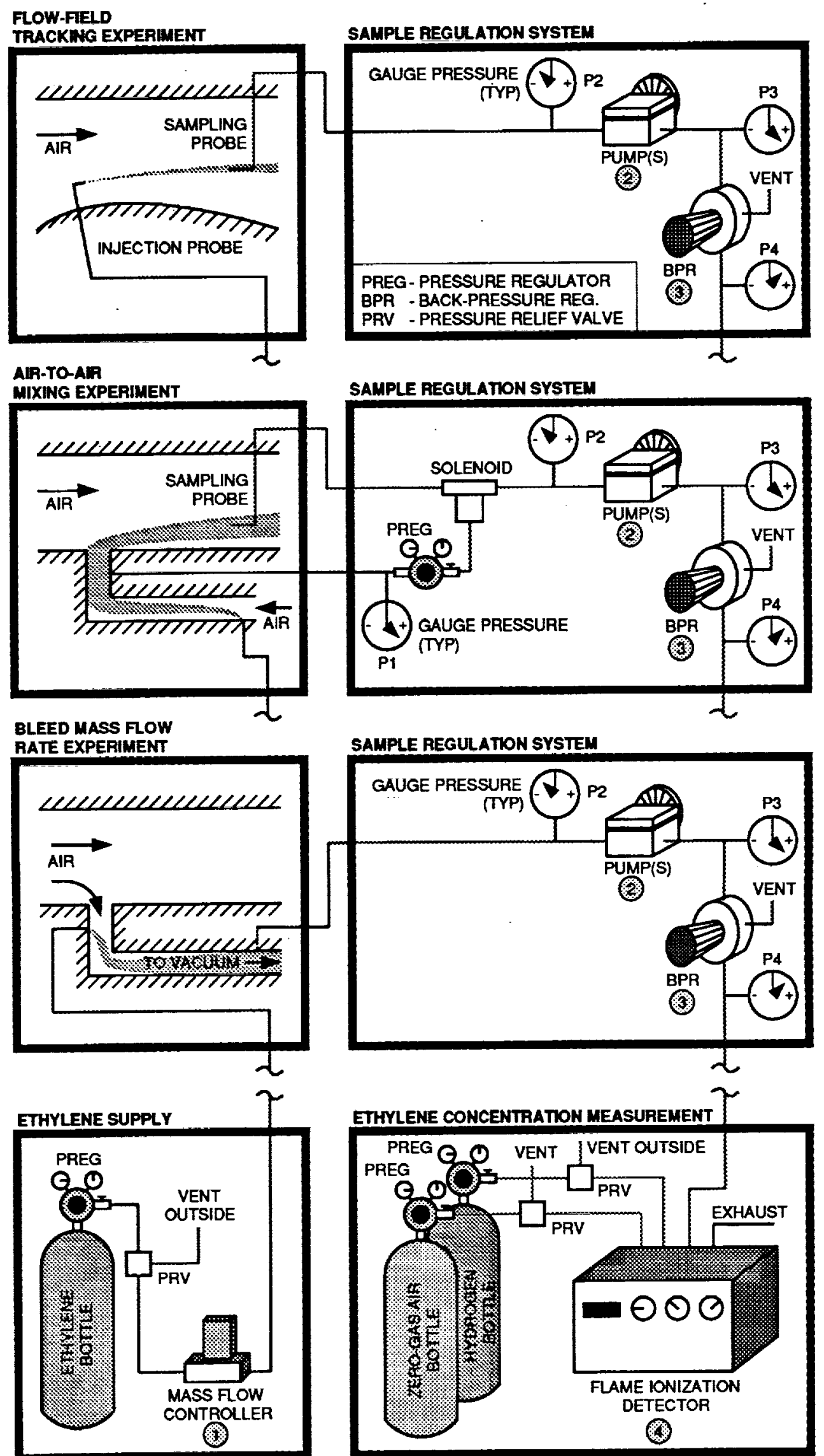

Fig. 1 Ethylene trace-gas system schematic. 
Table 1 Ethylene Trace-Gas System Equipment

\begin{tabular}{||c|l|l|r||}
\hline \hline $\begin{array}{c}\text { Item No. } \\
\text { (see Fig. 1) }\end{array}$ & \multicolumn{1}{|c|}{ Description } & \multicolumn{1}{|c|}{ Manufacturer/Model No. } & $\begin{array}{r}\text { Approx. } \\
\text { Cost (\$) }\end{array}$ \\
\hline \hline 1 & $\begin{array}{l}\text { Mass Flow Controller } \\
\text { Auto Flow Control \& Display }\end{array}$ & $\begin{array}{l}\text { Edwards/Model 825 } \\
\text { Edwards/Model 1511 (optional) }\end{array}$ & 600 \\
\hline 2 & Sample Pump & KNF Neuberger/Model N726.3ANI & 1200 \\
\hline 3 & Back-Pressure Regulator & Veriflo Corporation/BPR 30 & 200 \\
\hline 4 & FID & Gow-Mac Instrument Co./Model 23-500 & 4000 \\
\hline \hline
\end{tabular}

\section{Ethylene Trace-Gas Apparatus}

The components of the ethylene trace-gas system can be classified by ethylene supply and injection, gas sampling and pressure regulation, and concentration measurement (see Fig. 1). The major components of the trace gas apparatus are listed in Table 1 and are identified by the circled numbers in Fig. 1. The costs listed in Table 1 are for reference and represent what NASA paid for the components. All components were purchased within the last five years.

The ethylene trace-gas technique relies on the detection of a hydrocarbon gas. It is very important that all components be of the oil-less/grease-less type and not contain any materials that can out-gas hydrocarbons. Prior to assembly, all connecting lines should be flushed with acetone and then blown dry with zero-gas air (air containing less than $0.5 \mathrm{ppm}$ total hydrocarbons). After assembly, all connections should be leak checked.

For accurate measurements, the wind tunnel should also be as hydrocarbon-free as possible. Sources of hydrocarbons in the wind tunnel include oil from compressors, residual oil from flow visualization and residual cleaning solvents. Contamination of the air will show up as a background noise level. The air supplied to the NASA Lewis wind tunnels typically has a background level of 2-3 ppm equivalent ethylene. Residual hydrocarbons on the tunnel surfaces will cause artificially high readings when the sample probe is on the wall.

IMPORTANT SAFETY TIP: The ethylene tracegas technique involves two potentially hazardous gases: ethylene and hydrogen. For reference, the limits of inflammability in terms of percent volume in air for these gases are given in Table 2.11 Failure to observe appropriate safety precautions would be bad.

Table 2 Limits of Inflammability in Air (percent volume).

\begin{tabular}{||c|c|c||}
\hline Gas & Lower & Upper \\
\hline \hline Ethylene $\left(\mathrm{C}_{2} \mathrm{H}_{4}\right)$ & 2.75 & 28.60 \\
\hline Hydrogen $\left(\mathrm{H}_{2}\right)$ & 4.00 & 74.20 \\
\hline
\end{tabular}

Concentration Measurement

The instrument used to measure ethylene concentration is a flame ionization detector (FID). The FID consists of a small bumer within which a fuel and oxidizer are mixed and burned. Hydrogen and zero-gas air, are used as fuel and oxidizer, respectively, so there are no hydrocarbons present in this flame. When the sample is mixed with the flame, hydrocarbons are bumed and the carbon atoms become ionized. The carbon ions and electrons pass between two electrodes, decreasing the resistance between the electrodes and thus permitting an electric current to pass. This current is directly proportional to the amount of carbon ions present. The FID responds to both the amount of carbon atoms present in the sample, and the rate at which the sample passes through the detector. This makes it very important to maintain a constant flow rate of sample through the FID. For the FID unit used in the present system (Item 4 in Table 1) the maximum sensitivity occurs when the sample flow rate is maintained at $30 \mathrm{sml} / \mathrm{m}$. This flow rate is set by adjusting the sample pressure $P 4$ which is controlled by a $0-5$ psig back-pressure regulator built into the FID unit.

The primary disadvantage to using an FID to measure concentration is the relatively long response times to changes in conditions. Data supplied with the FID unit shows that at the optimum sample flow rate of 30 $\mathrm{sml} / \mathrm{m}$, a step input to the unit of $5.3 \mathrm{ppm}$ of methane $\left(\mathrm{CH}_{4}\right)$ requires approximately 10 seconds to reach $99.9 \%$ of the input concentration. This then represents the lower limit of response time when conditions change. However, what really controls system response is the time required to completely purge the system of an old sample when sample concentration changes. This will be addressed in a later section.

Calibration of the FID is accomplished by passing a sample of zero-gas air through the unit to establish a zero and then passing a reference ethylene-in-air mixture to set the span. The uncertainty in the concentration of the reference gases is less than $0.5 \mathrm{ppm}$. The manufacturer of the FID unit quotes an accuracy of $\pm 1.0 \%$ of full scale with full scale being $1000 \mathrm{ppm}-a$ absolute uncertainty of $\pm 10 \mathrm{ppm}$. Since the uncertainty in the calibration mixtures is an order of magnitude lower than the accuracy 
of the FID, we can assume that they contribute negligibly. to the overall uncertainty.

\section{Ethylene Supply and Injection}

The ethylene supply system consists of a highpressure ethylene bottle, a pressure regulator, a pressure relief valve and a mass-flow controller. The pressure regulator reduces the pressure from the high-pressure bottle to a range acceptable to the mass-flow controller. The pressure relief valve protects the mass-flow controller from over-pressure in the event of a regulator failure and should be vented outside to avoid producing a combustible mixture in the test area. The range of the massflow controller is primarily dependent on the mass-flow rate of the host flow, but also depends on the objective of the experiment. The mass-flow controller used in the present system (Item 1 in Table 1) features the ability to vary its full scale range anywhere between $5 \mathrm{sml} / \mathrm{m}$ and $5 \mathrm{sI} / \mathrm{m}$ by simple hardware changes.

Introduction of the ethylene into the host flow may be accomplished by injection probes or through surface taps depending on the objectives of the experiment. The most common injection probe is an L-shaped probe, like a downstream facing Pitot probe. Previous studies that have employed the ethylene trace-gas technique have included the results of experiments designed to measure and minimize disturbances from L-shaped type injection probes. 2, 3, 5, 12,13 For low speed applications, the Lshaped probe is simply cantilevered into the flow-field. For high-speed subsonic flow, deflection of the probe may become excessive and a catenary design must be used. ${ }^{10}$ At supersonic speeds, injection probes may produce unacceptable flow interference so that flush surface taps may be necessary for injection. We should note, however, that injection of the ethylene into a region of spanwise vorticity (the boundary-layer) will always produce some axial vorticity and enhanced mixing. Although this effect can be minimized by using low injection rates through small holes, it should be considered when interpreting results.

\section{Sampling}

To measure the ethylene concentration downstream of its point of injection, fluid is extracted from the flowfield. This is usually accomplished with a probe much like a Pitot tube, along with the required pumps. One impediment to applying the ethylene trace-gas technique to higher speed flows has been the perceived need for isokinetic sampling of the flow field (i.e. sampling at a velocity through the probe opening that matches the local host flow velocity). Isokinetic sampling is actually not necessary to accurately measure the local concentration of trace-gas in a host gas flow. Injecting trace-gas into the flow field creates an Eulerian concentration field. The local value of the concentration in the flow field does not depend on the rate at which the sample is acquired.
However, if the sample velocity through the probe opening greatly exceeds the local host flow velocity the spatial resolution ability of the probe would deteriorate. This is generally not a concem in high-speed flows.

of much greater concern for high-speed flow applications is delivering the sample to the FID unit at a constant flow rate in a minimum amount of time. Parameters that affect response time are the total volume of the system and the mass-flow rate through the regulation system. To minimize response time, the system volume should be minimized and the mass-flow rate should be maximized. We should point out here that the flow rate through the sample regulation system can and should be greater than the optimum flow rate through the FID unit. Pressure in the system is controlled by a back-pressure regulator (Item 3 in Fig. 1) which controls the sample pressure $P 3$ by venting excess sample. This allows a much more rapid purging of the system than if conventional pressure regulators are used.

System volume can be most effectively minimized by keeping the total distance that the sample must travel to reach the FID unit as short as possible. In particular, the line between the back-pressure regulator and the FID should be kept as short as possible since it is downstream of the "purging" vent of the back-pressure regulator. Minimizing the diameter of the connecting lines between components, will also reduce volume. However, if the diameter becomes too small, the benefits of reduced volume will be negated by increased frictional losses.

The mass-flow rate through the system upstream of the back-pressure regulator is a function of the probe diameter and length, the pump capacity, and the impact pressure at the probe face. The probe diameter should be selected to be the largest diameter able to adequately resolve the largest concentration gradients in the flow-field. To maximize the flow rate, a pump should be selected that is able to choke the flow through the sampling probe at all locations in the flow-field. In the NASA Lewis $1 \times 1 \mathrm{ft}$. Supersonic Wind Tunnel (SWT) tests, a 0.686 $\mathrm{mm}(0.027 \mathrm{in})$ I.D. tube was used as a sample probe. The length from the tip to the sample pump was one meter. If we assume that the flow through the probe may be approximated by Fanno line flow, then the variation of Mach number along the probe is given by the following ordinary differential equation: ${ }^{14}$

$$
\frac{d M^{2}}{M^{2}}=\frac{\gamma M^{2}\left(1+\frac{\gamma-1}{2} M^{2}\right)}{1-M^{2}} 4 f \frac{d x}{D}
$$

where $f$ is the friction factor given by:

$$
f=\frac{16}{R e_{D}}
$$

if the flow is laminar through the tube. Equation I was solved for a range of sample probe inlet total pressures with the condition that the flow be choked at the exit (for maximum mass-flow). Fig. 2 shows the mass-flow 


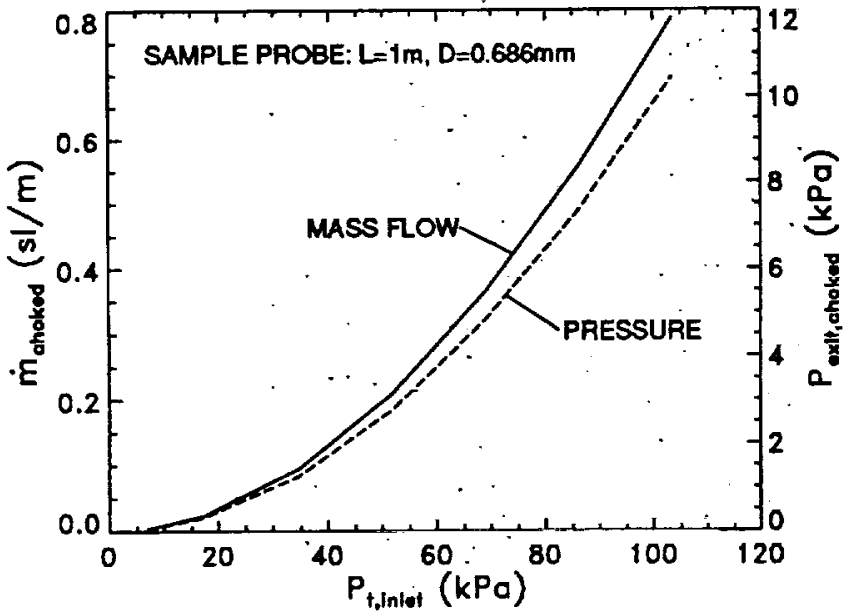

Fig. 2 Mass-flow and exit pressure of sample probe for choked conditions.

rate and exit pressure as a function of inlet total pressure. With the NASA Lewis $1 \times 1 \mathrm{ft}$. SWT operating at Mach 4 and a core total pressure of $275 \mathrm{kPa}$ (40 psia), the impact pressure at the face of the sampling probe as it rests on the wall is approximately $5 \mathrm{kPa}$ and represents the worst case in terms of pumping requirements. The data of Fig. 2 is replotted as choked mass-flow versus exit pressure in Fig. 3 and compared to the pump manufacturers performance. This plot shows that for all sample probe exit pressures, the pump is capable of delivering the mass-flow required for choked flow, and as a result, the sampling time is kept to a minimum.

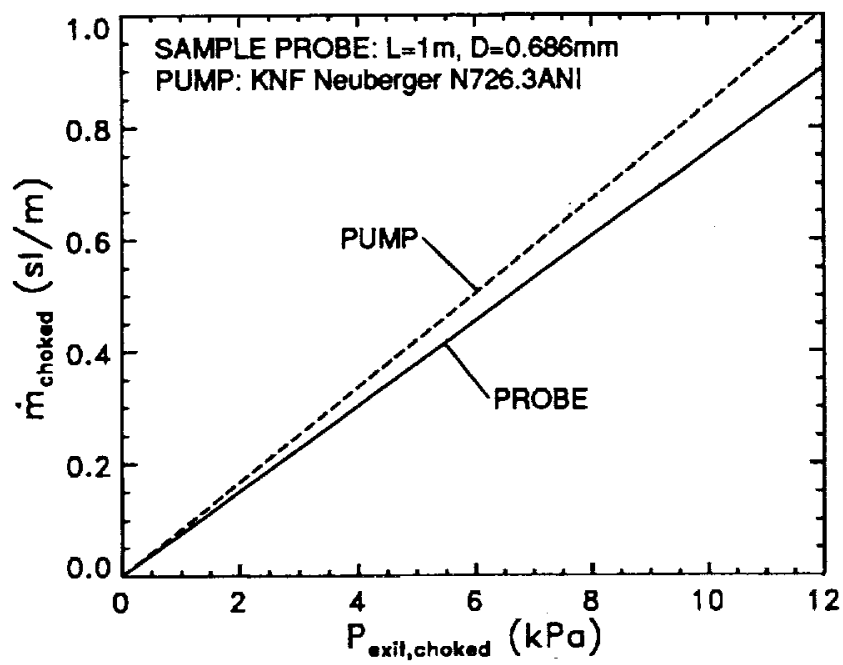

Fig. 3 Pump performance versus sample probe performance.

\section{Applications}

In this section, a description of each of the three applications will be given followed by an actual example.
Flow-Field Tracking

In the flow-field tracking application, the technique is used to deduce information about the flow-field from the trace-gas distribution. Interpretation of the measured trace-gas distributions can range from simple to downright ambiguous. In the simplest case, the technique is used more like a flow visualization technique and the result is simply to find where the fluid that passes through the injection point ends up at in the measurement plane. We call this streamline tracking and under most conditions the location of the peak concentration is approximately the location of the streamline that passes through the injection point. From here we can infer information about the turbulence structure and secondary flow by examining the spreading and distortion of the trace-gas distribution. Here is where the ambiguity arises because from the distribution alone it is sometimes difficult to determine the relative importance of convection and diffusion in the mixing of the trace-gas with the host flow. That is, similar distributions may be achieved by different processes, and therefore, additional information acquired by other measurement techniques may be required.

The trace-gas distribution can be quantified by computing the statistical moments of the distribution:

$$
\begin{gathered}
\bar{y}=E[y], \quad \bar{z}=E[z] \quad \text { (mean) } \\
\sigma_{y}^{2}=E\left[(y-\bar{y})^{2}\right] \\
\sigma_{z}^{2}=E\left[(z-\bar{z})^{2}\right] \quad \text { (variances) } \\
\sigma_{y z}=E[(y-\bar{y})(z-\bar{z})] \quad \text { (covariance) }
\end{gathered}
$$

where $E[\phi]$ denotes the expected value of a variable $\phi$ and is defined as:

$$
E[\phi]=\frac{\int \phi v d A}{\int v d A}
$$

Equation 3 represents the coordinates of the centroid of the distribution and under most conditions will nearly coincide with the coordinates of the peak concentration. The variances, equation 4 , are a measure of the spreading of the trace-gas in the $y$ and $z$ directions. The covariance, equation 5 , represents the orientation of the distribution. For a more complete discussion of the interpretation of the trace-gas distributions, see Reichert et al. ${ }^{9,10}$

With regard to injection, Reichert et al. have demonstrated that the rate of injection into the flow-field is largely unimportant. In other words, distributions measured with different injection rates, when normalized by the measured peak concentration, are the same.

To illustrate a high-speed flow-field tracking application, results from a crossing oblique shock-wave and boundary-layer interaction are presented. ${ }^{15}$ A schematic of the experiment with reference coordinates is shown 


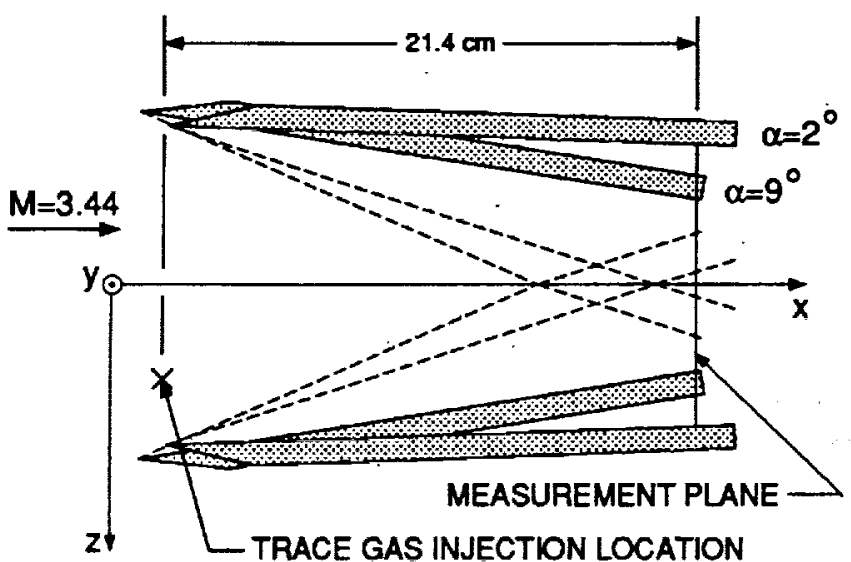

Fig. 4 Crossing shock-wave reference coordinates.

in Fig. 4. Supersonic flow $(M=3.44)$ passes between two sharp-edged plates at equal, but opposite, angles of attack to the flow. The resulting oblique shock-waves cross on the centerline and interact with the boundary layer $\left(\delta_{0}=3\right.$ $\mathrm{cm}$ ) developing on the $\mathrm{y}=0$ surface. Ethylene is injected through a surface static pressure tap at the location indicated by the " $x$ " and the concentration is measured in the indicated plane near the plate trailing edges. Volume fraction contours in the measurement plane are shown in Fig. 5 for various plate deflection angles. The volume fraction contour levels and the maximum volume fraction level indicated in the plot have been normalized by the peak concentration observed in the undisturbed boundary layer of the tunnel traveling the same axial distance (21.4 $\mathrm{cm}$ ). For deflection angles of $2^{\circ}$ and $6^{\circ}$, the location of the peak concentration remains on the surface, but is laterally displaced from the point of injection due to flow turning produced by the plates. Compared to the $\alpha=2^{\circ}$, the $\alpha=6^{\circ}$ case shows a greater degree of spreading which is due to larger turbulence intensities resulting from a deceleration of the local boundary layer flow by the adverse pressure gradient generated by the oblique shock-waves. In the vicinity of $y / \delta_{0}=0.2$ and $z / \delta_{0}=1.2$ for the $\alpha$ $=6^{\circ}$ case, the contours are distorted by a vortex that is known to be generated in a supersonic compression comer. ${ }^{16}$ For a deflection angle of $9^{\circ}$, the flow separates and the resulting large scale turbulent mixing greatly diffuses the ethylene trace. Under these conditions (flow separation), the location of the peak concentration can not be assumed to coincide with the streamline passing through the injection location. And speaking of separation, a variation of the flow-field tracking technique is the detection of reverse flow by injecting through a tap in the wall and sampling upstream. Flow reversal has occurred when the sample contains ethylene.

\section{Air-to-Air Mixing}

For air-to-air mixing applications, the injected air stream (see Fig. 1) is seeded with ethylene to a known concentration. The unseeded (stream 1) and seeded (stream 2) streams are allowed to mix and the ethylene

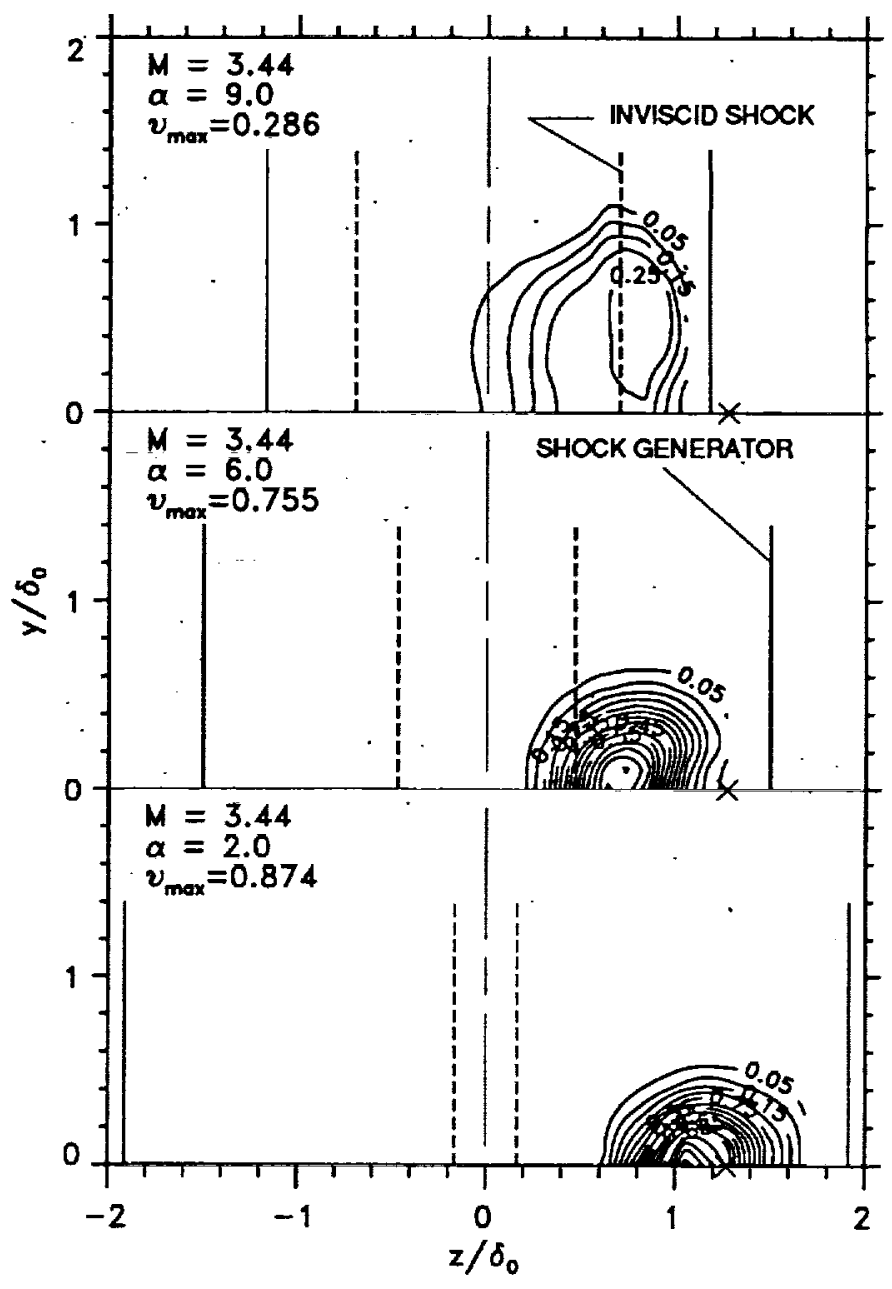

Fig. 5 Volume fraction contours for the crossing-shocks.

concentration in the mixing region is measured. When properly calibrated, the analyzer displays the volume (mole) fraction of ethylene, which for the present case is nearly equivalent to the mass fraction. Concentration levels measured in the mixing region, when normalized by the volume fraction of the seeded stream, gives the volume fraction of the seeded stream in the measurement plane:

$$
v_{2}=\frac{N_{2}}{N_{\text {total }}}=\frac{\left(N_{\text {eth }} / N_{\text {total }}\right)}{\left(N_{\text {eth }} / N_{2}\right)}=\frac{v_{\text {eth }}}{v_{\text {eth, ref }}}
$$

where $N$ is the number of moles.

Like the flow-field tracking application, the rate of injection of the ethylene is unimportant. It is very important, however, to know the concentration of ethylene in the injected stream before it is injected. To monitor the injected stream concentration, a reference sample line is teed into the regular sample line with a solenoid (see Fig. 1) which is occasionally energized to ensure that the reference concentration is not drifting.

Interpretation of the results for this application is very straight-forward. The resulting distribution computed from equation 7 represents the mean mixing of the 
two-streams and is very useful as a validation of CFD mixing models. A word of caution, however, is in order. The response time to analyze a sample is too long to represent anything other than a long time average of the concentration. That is, from the results there is no way of knowing if the two streams are mixed at the molecular level or if large eddies alternating between the two streams are passing the sample probe. This can be very important if the two streams represent reacting gases.

The fractional non-dimensional uncertainty associated with equation 7 is given by: $:^{17}$

$$
\begin{aligned}
\bar{W}_{v_{2}}^{2}=\left(\frac{W_{v_{2}}}{v_{2}}\right)^{2}= & \left(\frac{\partial \ln v_{2}}{\partial \ln v_{\text {eth }}} \cdot \frac{W_{v_{\text {eth }}}}{v_{\text {eth }}}\right)^{2}+ \\
& \left(\frac{\partial \ln v_{2}}{\partial \ln v_{\text {eth }, \text { ref }}} \cdot \frac{W_{v_{\text {eth }, \text { ref }}}}{v_{\text {eth }, \text { ef }}}\right)^{2}
\end{aligned}
$$

where $W$ is the absolute uncertainty of a variable. Substituting the expressions for the partial derivatives yields:

$$
\bar{W}_{v_{2}}=\sqrt{\left(1.0 \cdot \frac{W_{v_{\text {eth }}}}{v_{\text {eth }}}\right)^{2}+\left(-1.0 \cdot \frac{W_{v_{\text {eth }, \text { ref }}}}{v_{\text {eth }, \text { ref }}}\right)^{2}}
$$

The manufacturer of the FID unit quotes an accuracy of $1.0 \%$ of full scale. With the FID unit set for a full scale range of $1000 \mathrm{ppm}$ and the reference concentration of stream 2 set at $1000 \mathrm{ppm}$ (the FID has a 100\% overrange) equation 9 reduces to:

$$
\bar{W}_{u_{2}}=\sqrt{\left(\bar{W}_{v_{\text {eth }}}\right)^{2}+10^{-4}}
$$

This equation is plotted in Fig. 6 and shows the fractional uncertainty in the calculated volume fraction of Stream 2

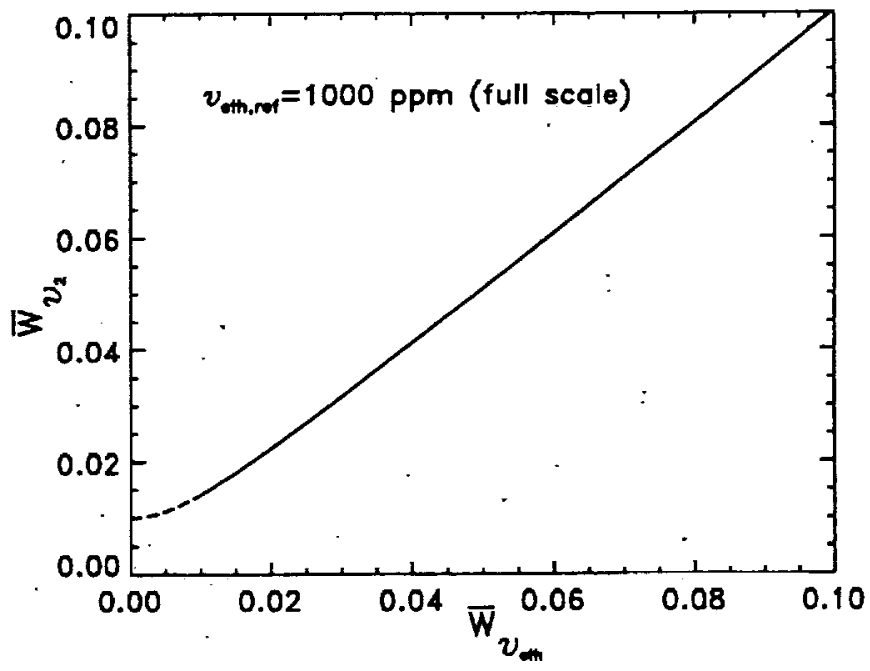

Fig. 6 Fractional uncertainty in volume fraction of the injected stream.

as a function of the fractional uncertainty in the measured volume fraction of ethylene. The dashed portion of the curve is unattainable since you can never measure an ethylene concentration greater than the concentration in the injected stream.

As an example of an air-to-air mixing application, the results of a wall-mounted hypermixing nozzle test are shown in Fig. $7 .^{18}$ In this example, supersonic flow $\left(\mathrm{M}=2.96, \delta_{0}=2.7 \mathrm{~cm}\right)$ passes over a contoured injector nozzle designed to enhance mixing through the generation of streamwise vorticity. The supply line to the injector nozzle was seeded with ethylene at a location approximately 60 supply line pipe diameters (pipe I.D. $=5.08$ $\mathrm{cm}$ ) upstream from the injector plenum to ensure thor-

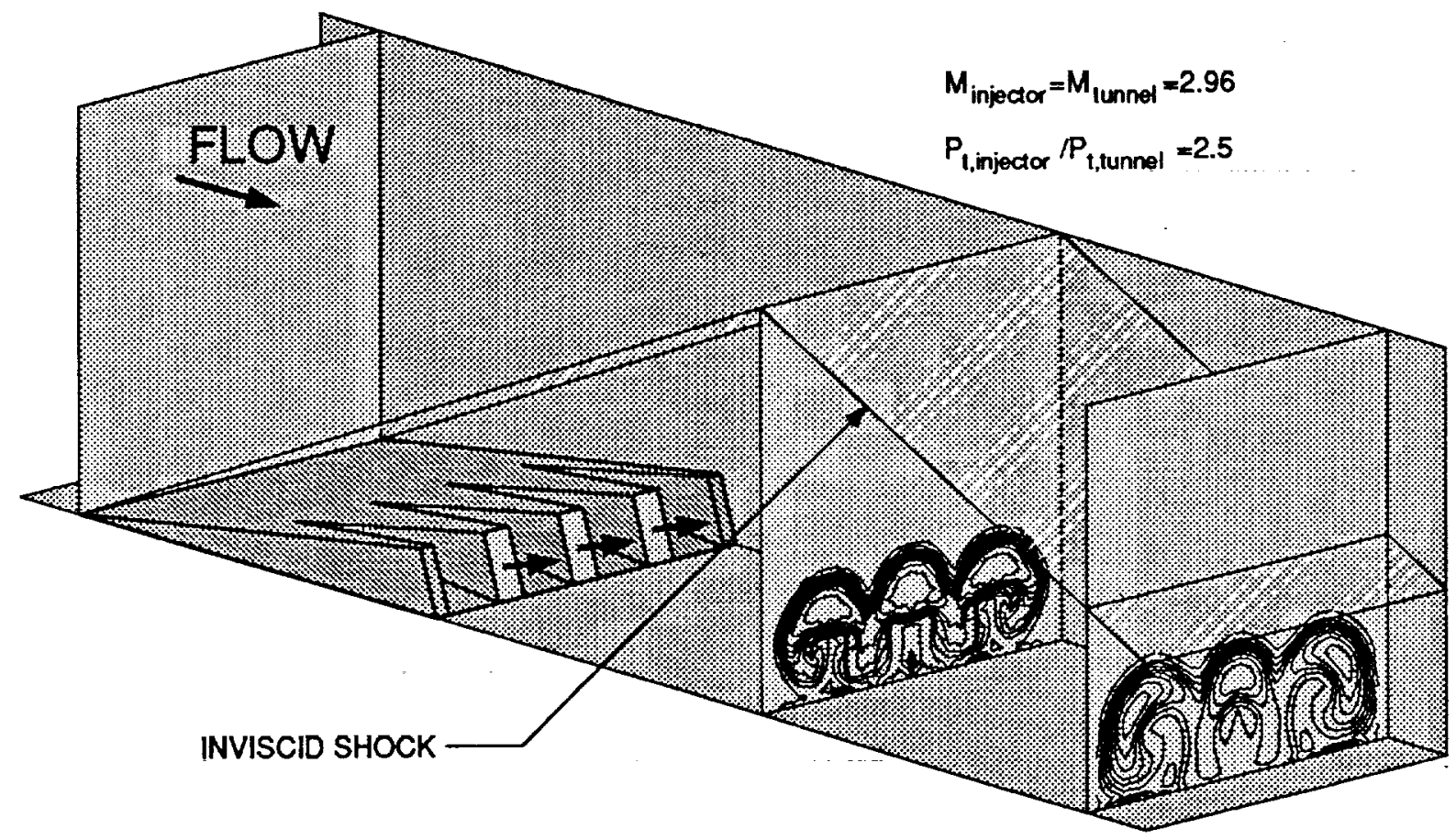

Fig. 7 Volume fraction contours for the hypermixing model. 
ough mixing. The ethylene concentration is measured in planes downstream of the nozzles and, when normalized by the reference injected concentration, yields the volume fraction of injected fluid. Volume fraction results for the hypermixing model have been used by Lee ${ }^{19}$ to validate the RPLUS computer code and by Davis ${ }^{20}$ to validate the SPARK-PNS computer code.

\section{Mass-Flow Measurement}

The ethylene trace-gas technique can be used as an altemative way of measuring bleed mass-flow rate when conditions are such that mass-flow measurement by other means is deemed unreliable. This situation may occur when the pressure and Reynolds number are very low and calibrated orifices lose accuracy. To apply the ethylene trace-gas technique to this problem, the bleed flow is seeded with ethylene at a known mass-flow rate. The bleed flow is than sampled at a downstream location where the ethylene is thoroughly mixed with the bleed stream. In a mixture of ethylene and air, the mass fraction of ethylene is defined in terms of the volume fractions as:

$$
\begin{aligned}
m f_{\text {eth }} & =\frac{M_{\text {eth }} v_{\text {eth }}}{M_{\text {eth }} v_{\text {eth }}+M_{a i r} v_{a i r}} \\
& =\frac{M_{\text {eth }} v_{\text {eth }}}{M_{\text {eth }} v_{\text {eth }}+M_{\text {air }}\left(1-v_{\text {eth }}\right)}
\end{aligned}
$$

where $M$ is the molecular weight of the gas. The mass fraction of ethylene can also be expressed in terms of the mass-flow rate of ethylene and air as:

$$
m f_{e t h}=\frac{\dot{m}_{e t h}}{\dot{m}_{e t h}+\dot{m}_{a i r}}
$$

Equating equations 11 and 12 and rearranging yields the following expression for the mass-flow of air:

$$
\dot{m}_{a i r}=\left(\frac{M_{a i r}}{M_{\text {eth }}}\right)\left(\frac{1-v_{e t h}}{v_{e t h}}\right) \dot{m}_{e t h}
$$

For accurate measurements, the bleed mass-flow must be steady and the ethylene must be thoroughly mixed. Steady flow can be ensured if a choke point is located somewhere in the bleed line-either the bleed plates themselves or through a valve if the plates are to be operated unchoked. One of the advantages of this technique is that the results are independent of the quality of the flow in the bleed line, i.e. the flow need not be uniform or assumed to have a particular velocity profile.

The propagation of uncertainty in measuring massflow via equation 13 can be expressed in fractional nondimensional form as:

$$
\frac{W_{\dot{m}_{a i r}}}{\dot{m}_{a i r}}=\sqrt{\left(\frac{-1}{1-v_{e t h}} \cdot \frac{W_{v_{e t h}}}{v_{e t h}}\right)^{2}+\left(\frac{W_{\dot{m}_{e t h}}}{\dot{m}_{e t h}}\right)^{2}}
$$

Since the (thoroughly mixed) volume fraction of ethylene is typically very small $\left(v_{e t h} \ll 1\right)$, equation 14 simplifies to:

$$
\bar{W}_{\dot{m}_{a i r}}=\sqrt{\left(\bar{W}_{\nu_{e t h}}\right)^{2}+\left(\bar{W}_{\dot{m}_{e t h}}\right)^{2}}
$$

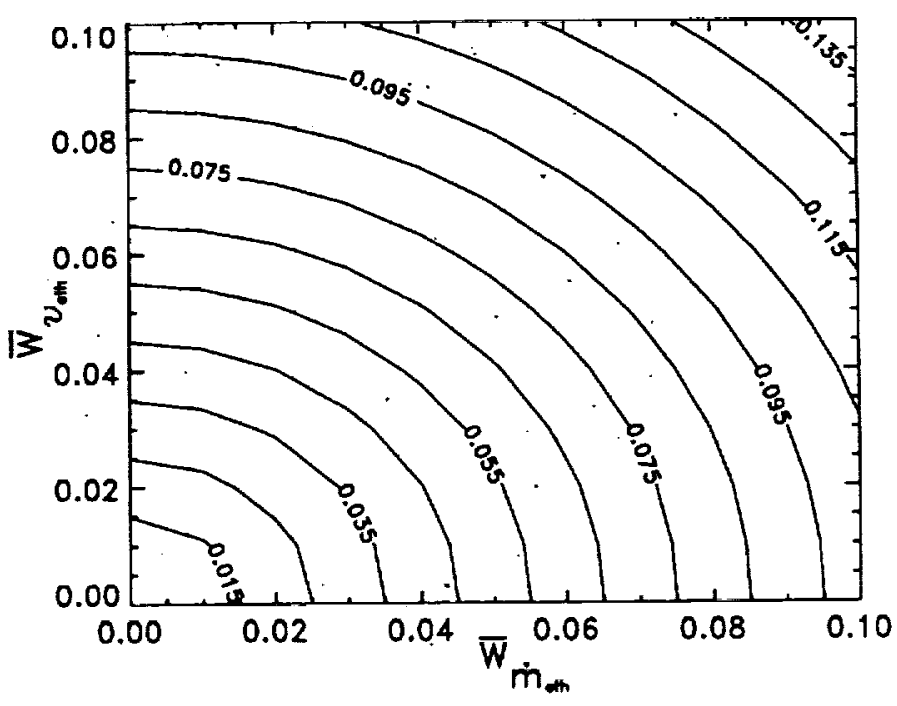

Fig. 8 Fractional uncertainty of the calculated air mass-flow rate.

Equation 15 is plotted in Fig. 8 and shows the fractional uncertainty in the calculated mass-flow rate of air as a function of the fractional uncertainty of the measured ethylene flow rate and volume fraction assuming that the calibration gas uncertainty is negligible.

To verify the validity of equation 13 , a small scale simulation of a bleed line was tested. Shown schematically in Fig. 9, a 4.5 meter length of $1.2 \mathrm{~cm}$ I.D. vacuum tube was used to simulate the bleed line. A valve was placed on the upstream end of the tube and the downstream end was connected to a vacuum pump. A reference mass-flow meter was placed in the middle of the tube. Ethylene was injected just downstream from the valve and a sample was taken from just upstream of the pump. Also placed in the line just downstream of the valve was a $15 \mathrm{~cm}$ mixing element. The air mass-flow rate was varied between 20 and $60 \mathrm{sl} / \mathrm{m}$ and at each set point of air mass-flow, the ethylene mass-flow was adjusted until a reading of $500 \mathrm{ppm}$ was obtained in the sample. Fig. 10 shows a plot of air mass-flow versus ethylene mass-flow. The data are shown reduced with two different calibration gases. One calibration gas was $505 \mathrm{ppm}$ of ethylene $\left(\mathrm{C}_{2} \mathrm{H}_{4}\right)$ and the other was $476 \mathrm{ppm}$ of propane $\left(\mathrm{C}_{3} \mathrm{H}_{8}\right)$. The analyzer can be calibrated to

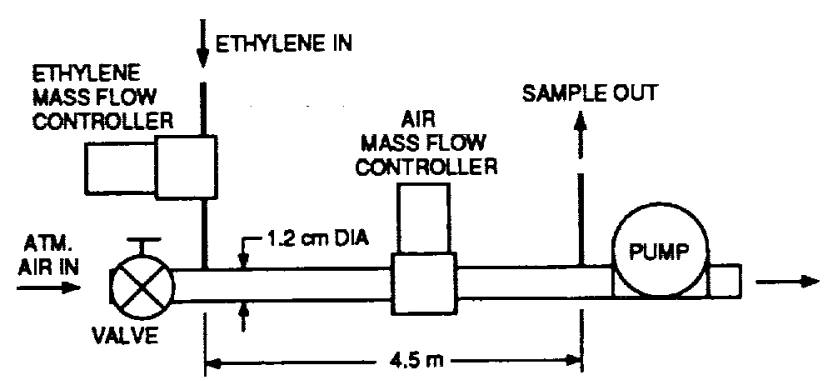

Fig. 9 Schematic of the bleed mass-fiow rate experiment. 


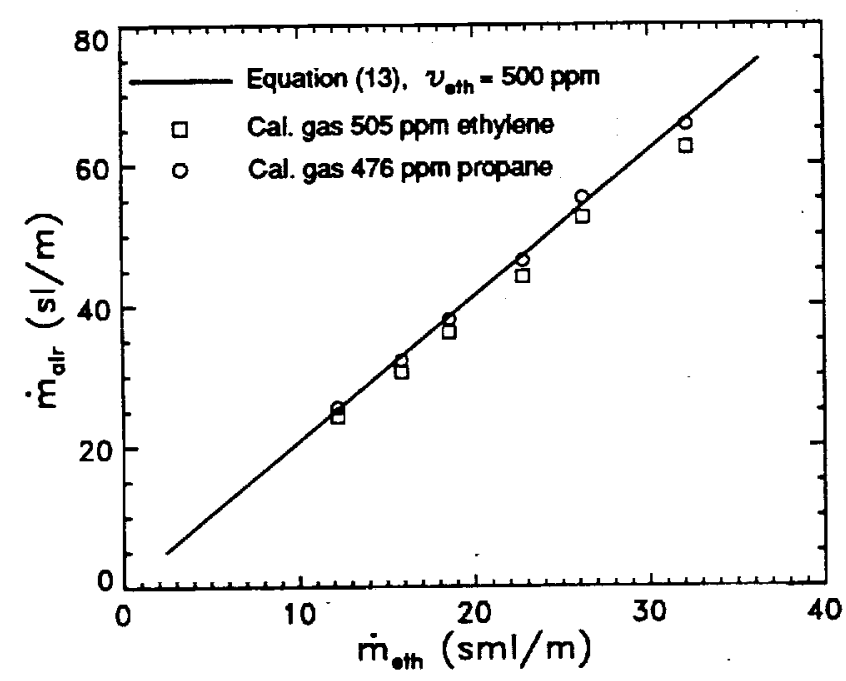

Fig. 10 Measured mass-flow rate for the bleed experiment.

propane if the reading is scaled by 1.5 -the ratio of carbon atoms in the molecules - so that $476 \mathrm{ppm}$ propane is equivalent to $714 \mathrm{ppm}$ ethylene. The different distributions resulting from the different calibration gases imply that either one of the calibration gases is not within specification or the FID unit has a non-linear response. A second FID unit was tested with virtually the same results. Nevertheless, the results are encouraging and with more refinement the technique should be a practical alternative to measuring mass-flow when other methods fail.

\section{Concluding Remarks}

Several applications of the ethylene trace-gas technique for diagnostic studies in high-speed flows have been presented. The primary advantage of the ethylene trace-gas technique is its simplicity and relatively low cost. Set-up time and post-test processing of the data is minimal. The primary limitation to the technique is the relatively long response times to changes in concentration, thus making the technique applicable only in steady flows. There are, however, two ways to increase the productivity of testing time. First, the use of a sampling probe rake with multiple trace-gas systems is a viable method to reduce testing time. The data for the air-to-air mixing example shown in Fig. 7 was accumulated using two trace-gas systems. In larger facilities, the cost of an additional system is easily offset by the reduction in the cost of wind-tunnel running time. The second method to increase productivity is to integrate the measurements with pressure type measurements. Pitot pressure can be recorded with the sampling probe if a solenoid is placed in the line to switch to a pressure transducer (actually, two solenoids are required since dead-heading the sample pump can extinguish the hydrogen flame in the FID). Another variation is to sample from the center tube of a three-hole cobra probe or a five or seven hole flow angle probe.

\section{Acknowledgment}

The authors would like to gratefully acknowledge Dr. W. R. Hingst, Dr. W. Faulkner, J. Bodner and B. Ramsey for their helpful contribution. We would also like to acknowledge D. Stark, A. Kane and G. Hurd for assembling the trace-gas system.

\section{References}

${ }^{1}$ Denton, J. D. and Usui, S., "Use of a Tracer Gas Technique to Study Mixing in a Low Speed Turbine," ASME Paper 81-GT-86, 1981.

${ }^{2}$ Smith, B. L., "Detection of Secondary Flow in a Turbine Cascade Using a Tracer Gas Technique," M.S. Thesis, Virginia Polytechnic Instibute and State University, Blacksburg, Virginia, Feb. 1983.

${ }^{3}$ Moore, J., "Flow Trajectories, Mixing, and Entropy Fluxes in a Turbine Cascade," Viscous Effects in Turbomachinary, AGARD, 1983, pp. 5-1 - 5-14. AGARD CP-351.

${ }^{4}$ Moore, J. and Smith, B. L., "Flow in a Turbine Cascade: Part II-Measurements of Flow Trajectories by Ethylene Detection," ASME Journal of Engineering for Gas Turbines and Power, Vol. 106, Apr. 1984, pp. 409-413.

${ }^{5}$ Gallimore, S. J., Spanwise Mixing in Multi-Stage Axial Compressors, Ph.D. Dissertation, University of Cambridge, Cambridge, England, Sept. 1985.

${ }^{6}$ Gallimore, S. J. and Cumpsty, N. A., "Spanwise Mixing in Multistage Axial Flow Compressors: Part 1 - Experimental Investigations," ASME Paper 86-GT-20, 1986.

${ }^{7}$ Bauer, R. C., "Fluid Migration and Mixing in a Multistage, Axial-Flow Compressor," M.S. Thesis, Iowa State University, Ames, Iowa, 1987.

${ }^{8}$ Wisler, D. C., Bauer, R. C., and Okiishi, T. H., "Secondary Flow, Turbulent Diffusion and Mixing in AxialFlow Compressors," ASME Journal of Turbomachinery, Vol. 109, Oct. 1987, pp. 455-482.

${ }^{9}$ Reichert, B. A., A Study of High Speed Flows in an Aircraft Transition Duct, Ph.D. Dissertation, Iowa State University, Ames, Iowa, 1991. (also NASA TM 104449).

${ }^{10}$ Reichert, B. A., Hingst, W. R., and Okiishi, T. H., "An Experimental Trace Gas Investigation of Fluid Transport and Mixing in a Circular-to-Rectangular Transition Duct," AIAA Paper 91-2370, 1991. (also NASA TM 104499).

${ }^{11}$ Weast, R. C., CRC Handbook of Chemistry and Physics, 66th ed., CRC Press, Boca Raton, FL, 1985.

${ }^{12}$ Gallimore, S. J., "Spanwise Mixing in Multistage Axial Flow Compressors: Part 2 - Throughflow Calculations Including Mixing," ASME Paper 86-GT-21, 1986.

${ }^{13}$ Moore, J., Moore, J. G., and Adhye, R. Y., "Testing Numerical Methods for Turbomachinary Flows Using Ethylene Injection Studies," Numerical Methods in Laminar and Turbulent Flows, edited by C. Taylor, W. G. Habashi, 
and M. M. Hafez, Pineridge Press, Swansea, U. K., 1987, pp. 1675-1686.

${ }^{14}$ Shapiro, A. H., The Dynamics and Thermodynamics of Compressible Fluid Flow, Vol. 1, John Wiley and Sons, New York, New York, 1953.

${ }^{15}$ Davis, D. O. and Hingst, W. R., "Surface and FlowField Measurements in a Symmetric Crossing ShockWave/Turbulent Boundary-Layer Interaction," AIAA Paper 92-2634, June 1992. (also NASA TM 106086).

${ }^{16}$ Kubota, H. and Stollery, J. L., "An Experimental Study of the Interaction Between a Glancing Shock Wave and a Turbulent Boundary Layer," Journal of Fluid Mechanics, Vol. 116, 1982, pp. $431-458$.
${ }^{17}$ Kline, S. J., "The Purposes of Uncertainty Analysis," ASME Journal of Fluids Engineering, Vol. 107, June 1985, pp. 153-160.

${ }^{18}$ Davis, D. O. and Hingst, W. R., "Progress Toward Synergistic Hypermixing Nozzles," AIAA Paper 912264, June 1991. (also NASA TM 105169).

${ }^{19}$ Lee, J., "A Numerical Study of Mixing in Supersonic Combustors with Hypermixing Injectors," AIAA Paper 93-0215, Jan. 1993.

${ }^{20}$ Davis, D. L., "Numerical Analysis of Techniques for Efficient Generation of Vorticity in Supersonic Flows," AIAA Paper 92-0828, Jan. 1992. 

Public reporting burden for this collection of information is estimated to average 1 hour per response, including the time for revlewing instructions, searching existing data sources, Public reporting burden for this collection of information is estimated to average 1 hour per response, including the timents regarding this burden estimate or any other aspect of this gathering and maintaining the data needed. and completing and reviewing Washecton Headquarters Services, Directorate for Information Operations and Reports. 1215 Jefferson collection of information, including suggestions

2. REPORT DATE 3. REPORT TYPE AND DATES COVERED

\begin{tabular}{|l|c|c|c|}
\hline 1. AGENCY USE ONLY (Leave blank) & $\begin{array}{c}\text { 2. REPORT DATE } \\
\text { February } 1994\end{array}$ & $\begin{array}{r}\text { 3. REPORT TYPE AND DATES COVERED } \\
\text { Technical Memorandum }\end{array}$ \\
\hline
\end{tabular}

\section{TITLE AND SUBTITLE}

Ethylene Trace-Gas Techniques for High-Speed Flows

6. AUTHOR(S)

WU-505-62-52

David O. Davis and Bruce A. Reichert

7. PERFORMING ORGANIZATION NAME(S) AND ADDRESS(ES)

National Aeronautics and Space Administration

Lewis Research Center

Cleveland, Ohio 44135-3191
8. PERFORMING ORGANIZATION REPORT NUMBER

E-8478

10. SPONSORING/MONITORING AGENCY REPORT NUMBER

NASA TM-106491

AIAA-94-0733

National Aeronautics and Space Administration

Washington, D.C. 20546-0001

\section{SUPPLEMENTARY NOTES}

Prepared for the 32nd Aerospace Sciences Meeting and Exhibit sponsored by the American Institute of Aeronautics and Astronautics, Reno, Nevada, January 10-13, 1994. Responsible person, Bruce A. Reichert, organization code 2660 , (216) 433-8116.

12a. DISTRIBUTION/AVAILABILITY STATEMENT 12b. DISTRIBUTION CODE

Unclassified - Unlimited

Subject Category 02

13. ABSTRACT (Maximum 200 words)

Three applications of the ethylene trace-gas technique to high-speed flows are described: flow-field tracking, air-toair mixing, and bleed mass-flow measurement. The technique involves injecting a non-reacting gas (ethylene) into the flow field and measuring the concentration distribution in a downstream plane. From the distributions, information about flow development, mixing and mass-flow rates can be determined. The trace-gas apparatus and special considerations for use in high-speed flow are discussed. A description of each application, including uncertainty estimates is followed by a demonstrative example.

14. SUBJECT TERMS

Instrumentation; Ethylene; Marking; High speed; Mixing; Diffusion; Mass flow rate

\begin{tabular}{l|c|c|}
\hline $\begin{array}{c}\text { SECURITY CLASSIFICATION } \\
\text { OF REPORT } \\
\text { Unclassified }\end{array}$ & $\begin{array}{c}\text { 18. SECURITY CLASSIFICATION } \\
\text { OF THIS PAGE } \\
\text { Unclassified }\end{array}$ & $\begin{array}{c}\text { 19. SECURITY CLASSIFICATION } \\
\text { OF ABSTRACT } \\
\text { Unclassified }\end{array}$ \\
\hline
\end{tabular}

